\title{
Desain Food Truck Zangrandi Sebagai Sarana Pendukung Media Promosi Untuk Kawasan Food Truck Area di Surabaya
}

\author{
Burhanuddin dan Andhika Estiyono \\ Departemen Desain Produk Industri, Fakultas Arsitektur Desain dan Perencanaan \\ Institut Teknologi Sepuluh Nopember \\ e-mail: andhika@prodes.its.ac.id
}

\begin{abstract}
Abstrak-Perancangan ini dilatarbelakangi oleh banyaknya kompetitor brand luar dalam kategori makanan dan minuman, sub-kategori toko es krim, berdasarkan sumber dari daftar Top Brand Index 2016 fase 2 dengan urutan Baskin Robbins 23,1\%, Zangrandi $7,8 \%$, Fountain $7,4 \%$, ragusa 3,2\%, Haagen-Dasz $3,0 \%$. Gencarnya pemasaran yang dilakukan oleh kompetitor mengakibatkan penurunan TBI ( Top Brand Index) sebesar 2-7\% tiap tahunnya dari awal tahun 2012 yang mengakibatkan turunnya minat terhadap brand lokal terutama Zangrandi yang berpusat di Jl. Yos Sudarso, Surabaya. Disertai dengan makin maraknya media promosi dengan sistem mobile, sebagai selling channel yang mulai banyak diminati saat ini yaitu food truck, yang memiliki area khusus tersebar dibeberapa pusat keramaian di Kota Surabaya. Zangrandi memerlukan sebuah rancangan food truck sebagai strategi media promosi dan pemasaran dalam merebut peluang pasar toko es krim di area Surabaya dan beberapa cabangnya yang tersebar di kota-kota besar. Tujuan perancangan ini untuk mendesain food truck Zangrandi sebagai media promosi dan optimalisasi distribusi produknya serta memecahkan permasalahan-permasalahan nyata yang ditemukan dalam perancangan visual promosi sebuah usaha food truck. Metode yang digunakan dalam penelitian adalah dengan melakukan deep interview dengan pengelola serta pendekatan ergonomi dan antropometri. Penulis juga ikut terjun langsung ke lapangan untuk mengetahui suasana yang sebenarnya. Hasil dari perancangan ini berupa desain food truck Zangrandi dengan konsep yang mempertahankan kesan klasik tempo dulu dan konfigurasi kabin pada interior platform untuk menunjang aktifitas operator serta sebagai media promosi yang sesuai dengan tuntutan perkembangan jaman dan diharapkan dapat meningkatkan penjualan produk dari Zangrandi.
\end{abstract}

Kata Kunci-Food Truck, Media Promosi, Zangrandi.

\section{PENDAHULUAN}

$\mathrm{E}^{\mathrm{s}}$ S KRIM ZANGRANDI adalah salah satu kedai es krim terkenal serta bersejarah di Surabaya yang memiliki desain interior klasik nuansa Belanda. Gedungnya asli bangunan Belanda. Namun aksesoris kayu kotak-kotak bercat putih tulang yang menempel di dinding serta langit-langit kedai memberi kesan nuansa Timur Tengah.

Kedai Es Krim Zangrandi memiliki sekitar 15 menu es krim yang mereka namakan menu specialities. Kisaran harga antara 36 ribu sampai dengan 55 ribu. Kedai Zangrandi juga menyediakan menu drink, slice ice cream, dan snack yang harganya di bawah harga menu specialities. setelah 85 tahun bertahan, kedai es krim Zangrandi sudah memiliki banyak cabang serta memiliki banyak variasi rasa.

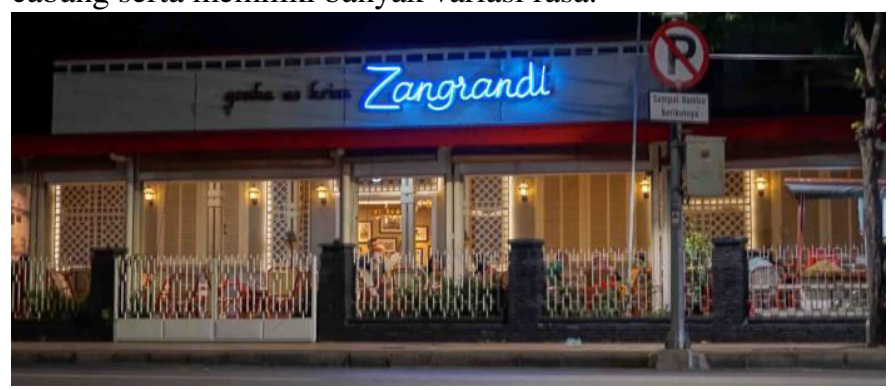

Gambar 1. Gedung Zangrandi yang berada di Jl. Yos Sudarso, Surabaya.

Produk Zangrandi saat ini mempunyai cakupan area distribusi di Surabaya, Malang, Jember, Jakarta dan Balikpapan. Konsumen yang dilayani berasal dari berbagai golongan dan hanya membeli untuk dikonsumsi pribadi. Penggunaan media promosi pada Zangrandi sangat berperan penting dalam menjual suatu produk ke konsumen secara langsung.

Persaingan pasar industri kuliner pada saat ini menuntut Zangrandi sebagai pelaku usaha untuk saling bersaing dalam memasarkan dan menjual produknya. Perusahaan harus menggunakan strategi yang tepat dan efisien untuk mempertahankan produknya agar tetap dikonsumsi oleh konsumen secara terus menerus. Oleh karena itu, hal penting perlu dilakukan dan diperhatikan oleh pelaku usaha bagaimana caranya untuk menciptakan pelanggan yang baru dan mempertahankan pelanggan yang lama.

Pada tahun 2016, metode penjualan dengan sistem mobile yaitu food truck, sudah mulai dikenal oleh masyarakat kota Surabaya tidak lepas dari usaha perusahaan yang menggunakan promotion mix untuk memperkenalkan produknya dan membuat citra di benak konsumen dan calon konsumen. Tentunya itu bertujuan untuk menarik perhatian konsumen dan memberikan pilihan konsumen dalam memutuskan untuk membeli produk food truck yang mereka inginkan.

Terdapat pula lahan khusus di Kota Surabaya dan sekitarnya yang disediakan oleh pengelola lahan untuk dijadikan area food truck yang mendukung aktivitas dan operasionalnya membuat kepopuleran food truck semakin dikenal sebagai pilihan dan memperkaya wisata kuliner yang fresh dan berbeda 


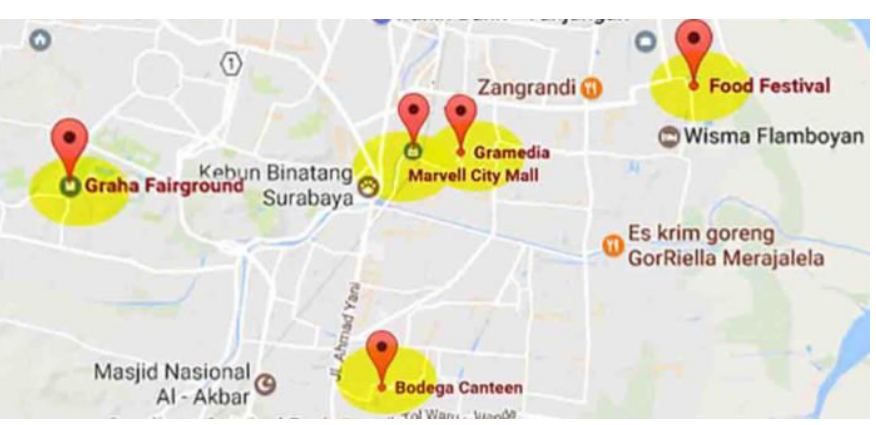

Gambar 2. Lokasi area food truck di Kota Surabaya.

Merek mempunyai peranan penting dalam dalam mempengaruhi keputusan konsumen untuk membeli. Hal ini dinyatakan dengan gambar berikut.

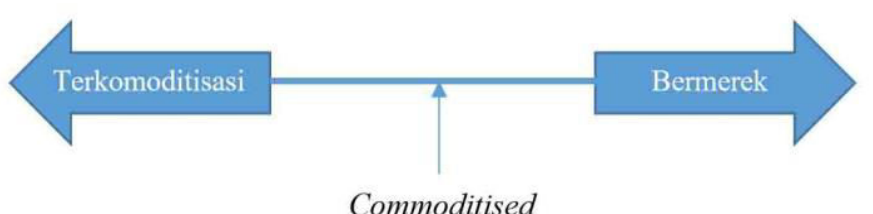

Gambar 3. Garis kontinum merek terhadap keputusan pembelian.

Berdasarkan teori diatas, dapat disimpulkan bahwa brand berperan penting dalam pengambilan keputusan pembelian. Setelah melihat kondisi di lapangan dan pemilihan objek penelitian tersebut berdasarkan pertimbangan dengan fenomena food truck yang mempunyai area khusus di kota Surabaya, sehingga penulis tertarik untuk melakukan perancangan desain food truck untuk brand legendaris Kota Surabaya yaitu Zangrandi Ice Cream dengan produk dan fasilitas yang diharapkan menciptakan suasana kuliner baru khususnya di Surabaya bahkan mampu berkembang di daerah lain di Indonesia sebagai strategi pemasaran media promosi untuk mengikuti tren pada saat ini. Perancangan ini dikembangkan berdasarkan prinsip ergonomi dan antropometri, agar diperoleh area pembagian aktivitas yang efektif dan nyaman serta aman, serta desain yang dibuat haruslah dibuat efisien sekaligus mempertahankan unsur klasiknya.

\section{A. Rumusan Masalah}

Sesuai dengan uraian latar belakang penelitian di atas, maka rumusan masalah yang akan dibahas adalah sebagai berikut :

1. Bagaimana menerjemahkan identitas Zangrandi dalam rancangan desain food truck

2. Bagaimana merancang desain food truck yang mempunyai daya pikat di tempat yang dituju

3. Bagaimana merancang desain interior food truck yang menunjang kegiatan operator

4. Bagaimana merancang desain food truck sebagai penunjang media promosi Zangrandi untuk bersaing dengan kompetitor.

\section{B. Batasan Masalah}

Batasan masalah dibuat dengan tujuan agar perancangan yang dilakukan lebih terfokuskan. Berikut adalah batasan masalahnya:

1.Perancangan desain dari sudut styling desain, teknologi, mesin, dan fasilitas food truck sesuai dengan karakter serta filosofi food truck yang dikonsep untuk Zangrandi.

2. Penggunaan food truck sebagai media promosi di area food truck di Surabaya

\section{Tujuan}

1. Menghasilkan desain food truck berupa interior beserta komponen-komponennya yang mampu mengakomodasi kebutuhan operator.

2. Menghasilkan desain eksterior dan interior platform food truck yang mampu memberikan kenyamanan interaksi antara penjual dan pembeli.

3. Menghasilkan desain food truck yang dapat mewakili eksistensi dari Zangrandi

4. Menghasilkan desain untuk memunculkan kesan kuat dari karakteristik Zangrandi

\section{Manfaat}

1. Mendesain food truck yang kemudian diharapkan dapat menunjang fasilitas dan memberikan pengalaman yang baru serta tambahan wawasan bagi pengunjung yang datang ke food truck ini.

2. Mendesain eksterior food truck dengan nuansa baru untuk masyarakat umum dengan studi aplikasi desain yang representatif.

\section{METODOLOGI PERANCANGAN}

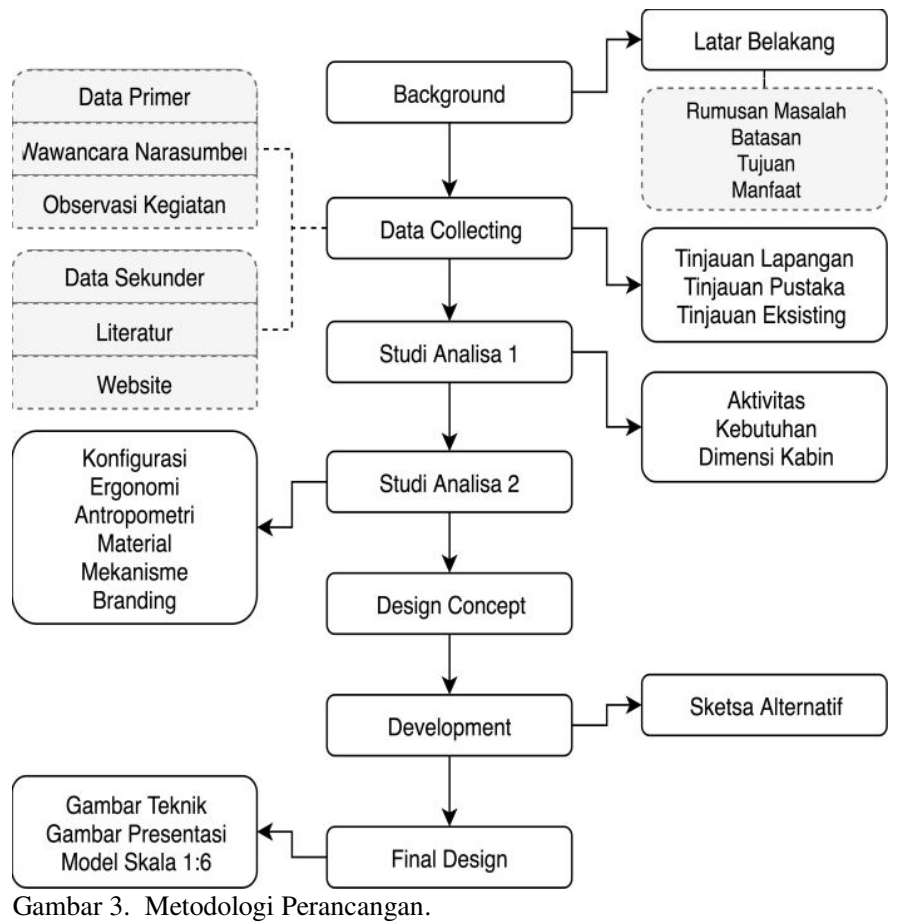

\section{A. Studi Analisa Aktifitas}

Studi ini berfungi suntuk mengetahui berbagai macam aktifitas dari setiap peran dalam kegiatannya. Terdapat setidaknya 3 peran aktifitas yang di analisa yaitu konsumen, 
operator 1 dan operator 2 .

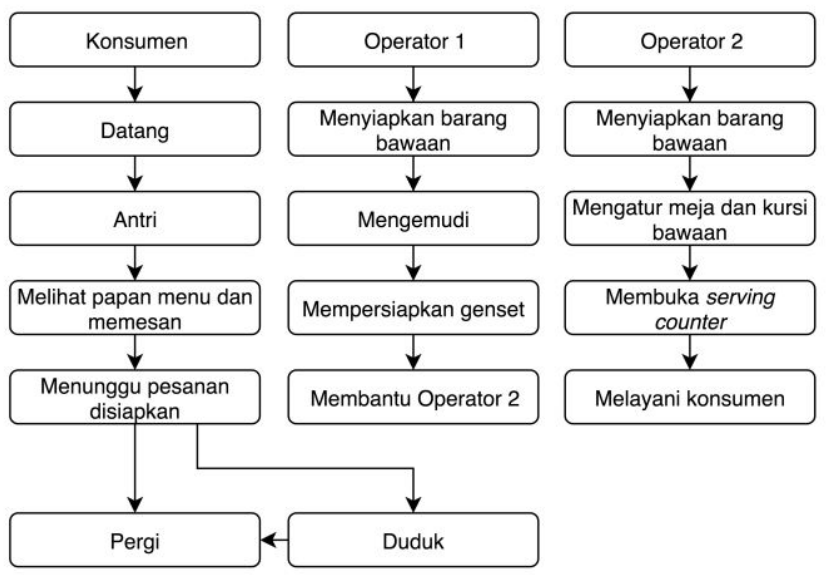

Gambar 4. (a) kerangka aktifitas konsumen, (b) kerangka aktifitas operator 1 dan (c) kerangka aktifitas operator 2.

Aktifitas yang diteliti disesuaikan dengan alur kegiatan pelayanan pegawai Zangrandi pada saat melayani konsumen dengan kegiatan operasional food truck pada umumnya.

\section{B. Studi Analisa Kebutuhan}

Studi analisa kebutuhan dalam perancangan food truk ini antara lain adalah kompartmen utama dalam menyimpan es krim yaitu Sliding Curve Glass Freezer yang mempunyai dimensi paling besar dan kompartmen lain untuk menyimpan buah-buahan dan macam-macam varian topping es krim. Agar area gerak 2 operator di dalam kabin food truk semakin luas maka harus memilih kompartmen yang mempunyai dimensi yang mumpuni untuk dimensi kabin yang terbatas.

Tabel 1.

Kebutuhan Barang Bawaan

\begin{tabular}{clc}
\hline \hline No. & \multicolumn{1}{c}{ Kompartmen } & Dimensi (mm) \\
\hline 1 & Sliding Curve Glass Freezer & $990 \times 705 \times 875$ \\
2 & Mini Bar Fridge & $439 \times 470 \times 540$ \\
3 & Up Right Glass Door Freezer & $595 \times 508 \times 615$ \\
4 & Condiment Dispenser Rail & $560 \times 140 \times 150$ \\
5 & Countertop Condiment Dispenser & $704 \times 108 \times 100$ \\
6 & Generator Set & $590 \times 430 \times 435$ \\
\hline \hline
\end{tabular}

\section{Studi Analisa Dimensi Kabin}

Studi analisa dimensi kabin ini ditujukan untuk membagi area sesuai dengan hasil analisa aktifitas dan daya tampung kabin platform food truck menggunakan metode blocking area. Dalam proses ini dilakukan berbagai macam studi mulai dari pemilihan platform, pemilihan konfigurasi bentuk dapur hingga ergonomi dan antropometri antara konsumen dan operator.

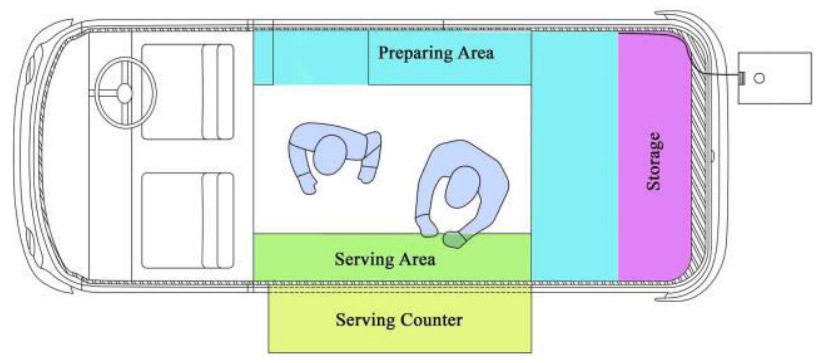

Gambar 5. Blocking Area food truck sesuai aktifitas dan kebutuhan.

\section{Studi Analisa Bentuk}

Studi analisa bentuk ini berkaitan dengan bentuk body platform yang berdampak pada dimensi dalam kabin. Selain kabin platform tanpa ubahan bentuk body. Bentuk body platform food truck memiliki 2 tipe yaitu kabin sesuai body sengan tambahan high roof dan cabin berbentuk box dengan platform kendaraan jenis pick-up. Kabin body high roof memiliki dimensi lebar dan tinggi sesuai dengan bentuk dasar bagian depan platform tersebut. Sementara kabin box memiliki dimensi yang dapat di-custom sesuai dengan kebutuhan yang diinginkan.Untuk mengetahui jenis kabin yang akan dipakai, maka dibutuhkan analisa guna melihat kelebihan dan kekurangan dari kedua jenis kabin tersebut.

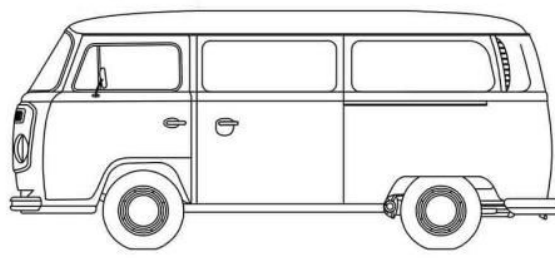

\section{Kabin Body}

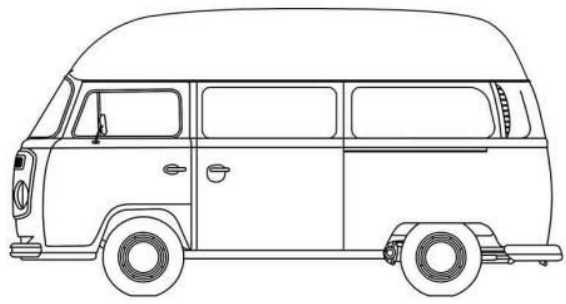

Kabin Body High Roof

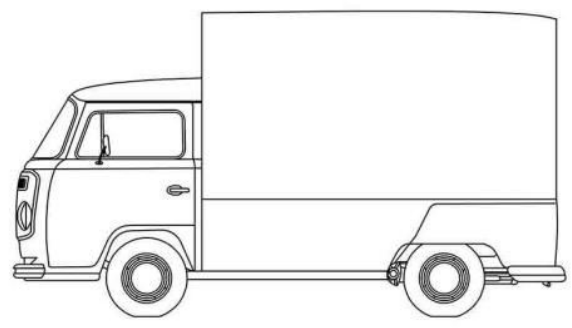

Kabin Box

Gambar 6. Perbandingan Bentuk Kabin Pada Platform.

Tabel 2.

Alat Ukur perbedaan Jenis Bentuk Kabin Pada PLatform

\begin{tabular}{|c|c|c|}
\hline $\begin{array}{l}\text { Jenis } \\
\text { kabin }\end{array}$ & Kelebihan & Kekurangan \\
\hline $\begin{array}{l}\text { Kabin } \\
\text { body }\end{array}$ & $\begin{array}{l}\text {-Tidak terkesan overload } \\
\text { - Bentuk serasi dan sealur } \\
\text { - Ramping }\end{array}$ & $\begin{array}{l}\text { - Interior sempit tidak dapat } \\
\text { melakukan aktifitas leluasa } \\
\text { - Peralatan yang dibawa } \\
\text { terbatas dengan dimensi } \\
\text { standar mobil }\end{array}$ \\
\hline $\begin{array}{l}\text { Kabin } \\
\text { box }\end{array}$ & $\begin{array}{l}\text { - Interior luas } \\
\text { - Dapat beraktifitas sesuai } \\
\text { kebutuhan karena memiliki } \\
\text { atap yang lebih tinggi } \\
\text { - Peralatan yang dibutuhkan } \\
\text { lebih bantak sesuai dengan } \\
\text { luas kabin yang ditentukan }\end{array}$ & $\begin{array}{l}\text { - Bentuk eksterior overload } \\
\text { - Bentuk cenderung lebih } \\
\text { besar dan kabin berbentuk } \\
\text { persegi }\end{array}$ \\
\hline
\end{tabular}

Berdasarkan kemampuan kapasitas, kabin box lebih diunggulkan karena dapat menambah kapasitas platform termasuk lebarnya. Namun sesuai dengan undang-undang tentang modifikasi mobil, bahwa tidak diperkenankan memperlebar badan mobil dan hanya dapat memperpanjang. 
Pemilihan akhir jatuh pada cabin body. Dengan kondisi lebar yang sama, cabin body terlihat lebih serasi dan harmonis ketimbang cabin box. Untuk mengatasi kekurangan maka dilakukan penambahan dimensi tinggi dan panjang kabin.

\section{E. Studi Analisa Konfigurasi}

Studi analisa konfigurasi ini untuk merancang konfigurasi desain kabin dapur yang terorganisir dan mempermudah alur kerja operator. Dari proses analisa menghasilkan tata letak sera urutan kegiatan yang lebih efisien sebagai berikut:

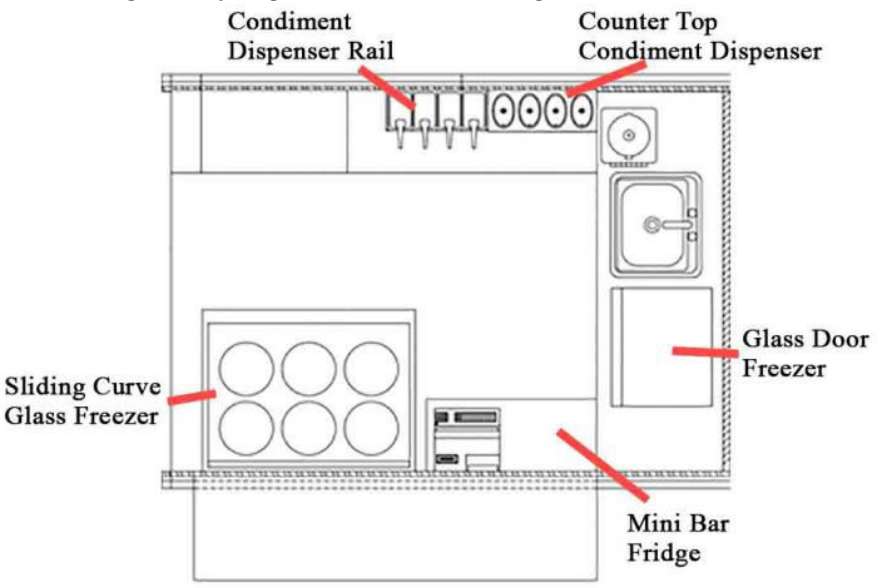

Gambar 7. Konfigurasi Kabin Dapur.

\section{F. Studi Analisa Ergonomi}

Studi ini bertujuan unutk mengetahui batasan dimensi antropometri tubuh manusia khususnya masyarakat Indonesia. Batasan mengacu pada standar buku "Human Dimension \& Interior" karya Julius Panero dengan 5, 50 dan 95 persentil yang disesuaikan ukuran tubuh orang Indonesia.

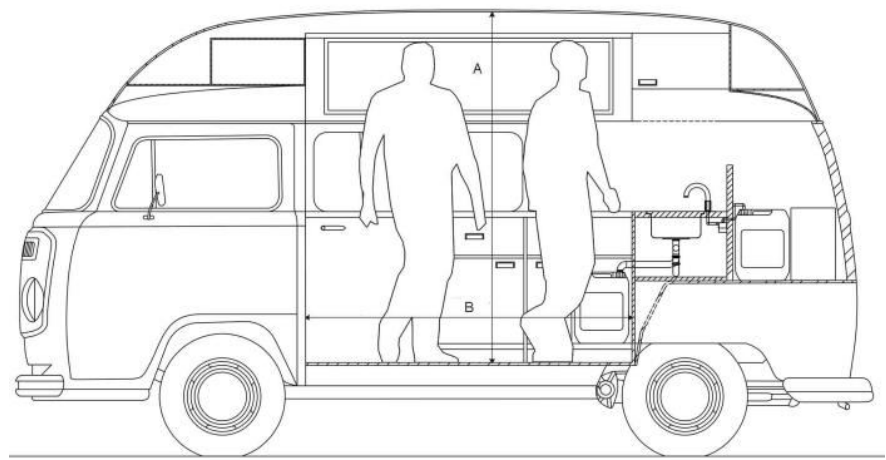

Gambar 8. Ergonomi Konfigurasi Kabin Tampak Samping.

Tabel 3.

Rekomendasi Ergonomi Dimensi Kabin

\begin{tabular}{clc}
\hline \hline Posisi & Area Kerja & Rekomendasi (mm) \\
\hline A & Tinggi atap kabin & $1800-1900$ \\
& & $1700-2000$ \\
B & Panjang kabin & \\
& & $600-1000$ \\
C & Lebar kabin & $1000-2000$ \\
D & Lebar serving counter & \\
& & \\
\hline \hline
\end{tabular}

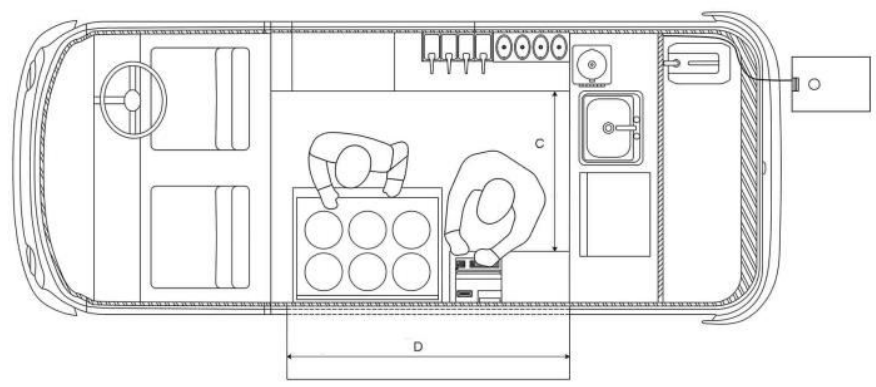

\section{G. Studi Analisa Material dan Produksi}

Ditujukan untuk mengidentifikasi material beserta proses produksinya untuk dianalisa guna menentukan struktur dan material terbaik untuk platform food truck serta memiliki proses produksi yang tepat yang diaplikasikan pada desain food truck Zangrandi.

\section{H. Studi Analisa Mekanisme}

Studi analisa mekanisme ditujukan untuk mendapatkan sistem mekanisme komponen platform yang optimal untuk kemudian diterapkan pada platform food truck Zangrandi. Komponen atap dan meja pada serving counter memerlukan mekanisme dengan sistem engsel dan parts lain seperti shock absorber untuk penahan atap.

\section{Studi Analisa Branding}

Studi analisa branding diperlukan untuk menerjemahkan identitas Zangrandi dalam rancangan desain food truck untuk membawa kesan klasik dari gedung Zangrandi yang masih dipertahankan sejak jaman Belanda. Dengan menggunakan inspiration board dijadikan dasar dari karakteristik desain platform food truck seperti bentuk, material, tone warna, finishing dan environment dari alternatif desain yang akan dirancang.

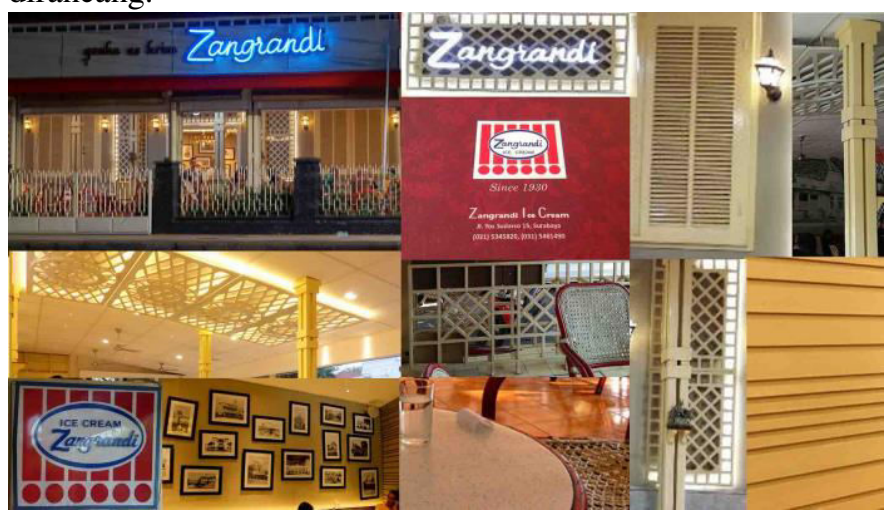

Gambar 10. Inspiriation Board.

\section{HASIL}

Dari berbagai studi yang dilakukan sebelumnya serta brainstorming, menghasilkan 5 poin utama untuk desain rekrutmen yaitu:

1.Recognizable : Dapat dikenali atau diidentifikasi orangorang sebagai Zangrandi Ice Cream Truck dengan ciri khasnya bernuansa klasik. 
2. Comfortable : Interior yang less stressful (agar operator tidak cepat merasa lelah), ergonomis dan terdapat ruang gerak yang cukup untuk operator.

3. Applicative : Desain dapat diterapkan di moda transportasi yang sudah ada, dan dapat diproduksi di industri karoseri lokal.

4. Carry Weight : Desain interior kabin yang dapat mengangkut komponen-komponen penting dalam pembuatan menu Zangrandi yaitu freezer, laci pendingin (undercounter freezer with drawers), pompa saus dispenser, topping dispenser, wastafel dan laci penyimpanan.

5.Achievable : Harga yang cukup terjangkau dibawah harga maksimum yang ditentukan perusahaan yaitu dibawah 200 juta.

\section{1) Gambar Presentasi}

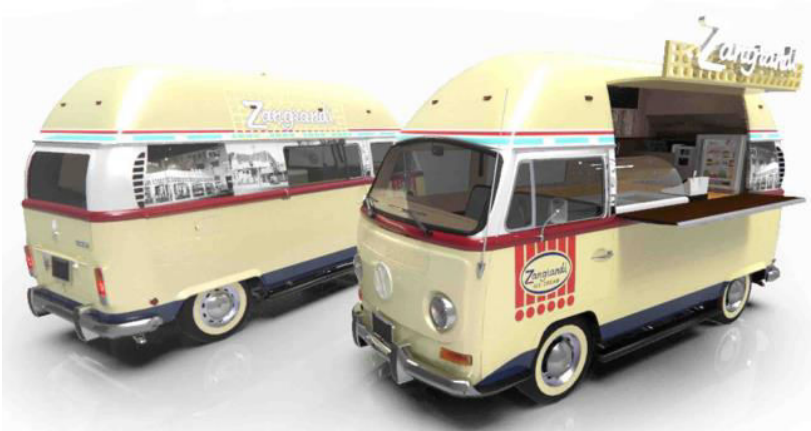

Gambar 11. Final Desain Eksterior Food Truck Zangrandi 1.

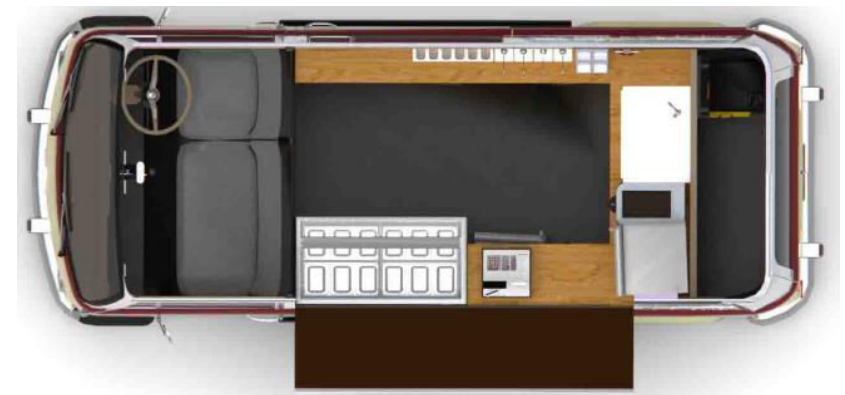

Gambar 12. Final Desain Interior Food Truck Zangrandi Tampak Atas.

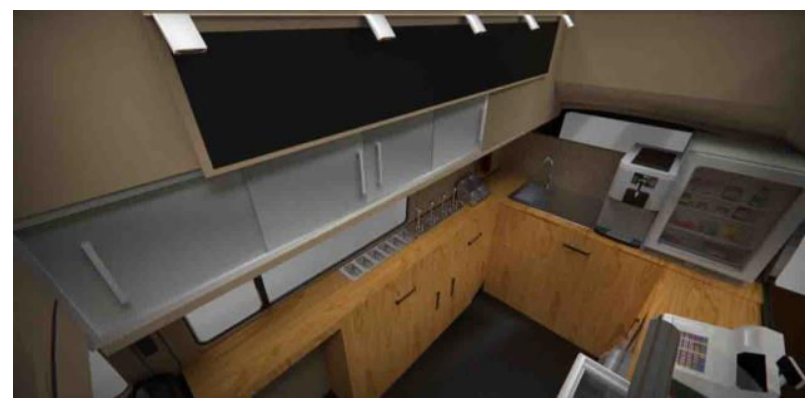

Gambar 13. Final Desain Interior Food Truck Zangrandi Perspektif (1).

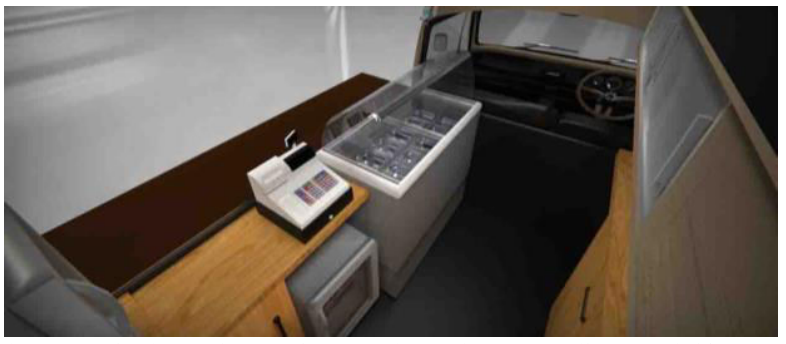

Gambar 14. Final Desain Interior Food Truck Zangrandi Perspektif (2).

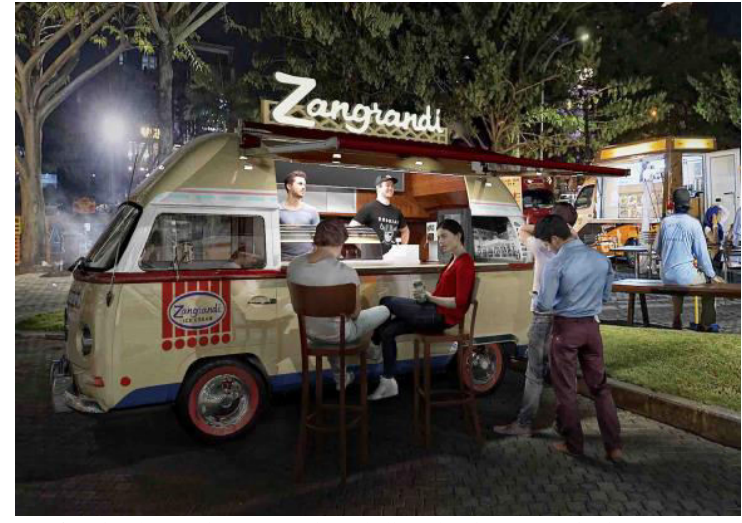

Gambar 15. Final Desain Operasional di Lokasi Yang Dituju.

2) Model Skala

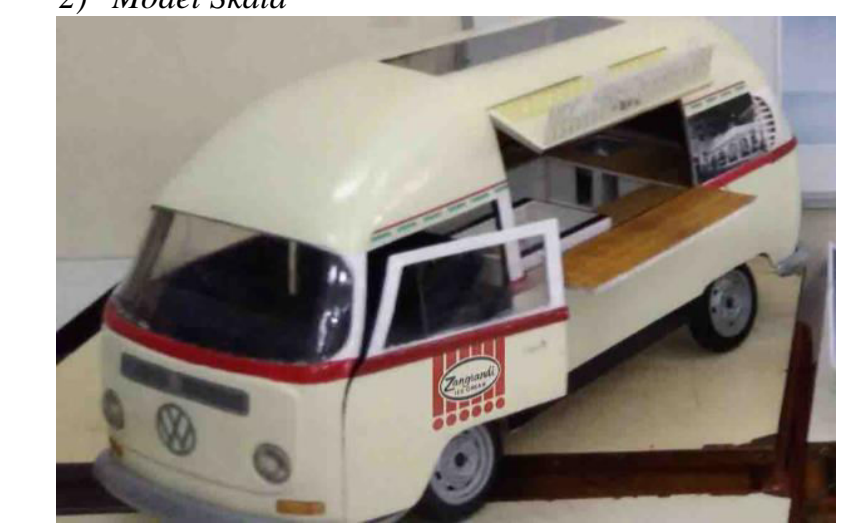

Gambar 16. Hasil Model Skala 1:6.

\section{KESIMPULAN/RINGKASAN}

Berdasarkan perumusan masalah, didapatkan kesimpulan dari "Desain Food Truck Zangrandi Sebagai Sarana Pendukung Media Promosi Untuk Kawasan Food Truck Area Di Surabaya" ialah sebagai berikut:

1.Food truck dengan konsep klasik yang diambil dari nilai historis dan bentuk-bentuk ciri khas dari gedung Zangrandi mampu menerjemahkan identitas Zangrandi kedalam rancangan platform food truck ini. sehingga konsumen loyal dapat merasakan nuansa Zangrandi di tempat yang berbeda dengan daya pikat tersendiri.

2. Rancangan desain food truck ini mampu menunjang event atau tempat yang mempunyai tema historis seperti musium agar menambah daya tarik minat pengunjung dengan daya pikat tersendiri.

3. Dengan kosep desain kabin interior terorganisir yang sudah melewati beberapa analisa ergonomi dan antropometri serta analisa dimensi kabin terhadap dimensi barang bawaan pada analisa kebutuhan menghasilkan area kerja yang efisien untuk menunjang aktivitas 2 operator.

4. Dengan adanya selling channel media promosi berupa food truck ini diharapkan Zangrandi tidak tergeser kedudukannya sebagai salah satu toko es krim ternama oleh kompetitor khsususnya dari produk luar negeri yang semakin memperluas ekspansi pasarnya secara nasional. 


\section{UCAPAN TERIMA KASIH}

Penulis A.F. mengucapkan terima kasih banyak kepada pihak yang ikut terlibat mulai dari pihak Zangrandi yang membantu penulis dalam saran, kritik dan semangat yang diberikan.

\section{DAFTAR PUSTAKA}

[1] B. M. Aritonang, "Redesain Sarana Bantu Jual PKL STMJ Dengan Brand Image 'Tempo Dulu,"” ITS Surabaya, 2008.

[2] I. Laviena, "Optimalisasi Distribusi Produk Bbq Street Dengan Menggunakan Food Truck," PERFORMA J. Manaj. dan Start-Up
Bisnis, vol. 1, no. 1, pp. 16-22, 2016.

[3] J. Panero and Z. Martin, Dimensi Manusia \& Ruang Interior. Jakarta: Erlangga, 2003.

[4] L. Sudanto, "Faktor-Faktor Yang Mempengaruhi Keputusan Konsumen Dalam Pembelian Ice Cream Produksi CV Zangrandi Di Surabaya," Surabaya, 1990.

[5] C. Sulaiman, "Analisis faktor faktor yang mempengaruhi loyalitas pelanggan es krim Zangrandi," Unversitas Kristen Petra, 2009.

[6] A. Tonoli, M. Lorenzo, L. R.R., and P. Giuseppe, "The Automotive Body Volume I Components Design,” Springer, 2011.

[7] I. C. Yonathan, "Pengaruh Kompetensi, Informasi, Karyawan Dan Bukti Fisik Terhadap Kepuasan Dan Loyalitas Konsumen Pada Zangrandi Di Surabaya," J. Hosp. Dan Manaj. Jasa, vol. 2, no. 1, pp. 107-119, 2013. 